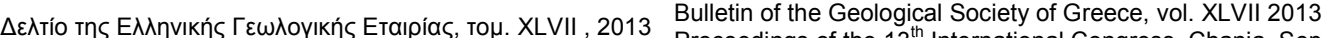
Proceedings of the $13^{\text {th }}$ International Congress, Chania, Sept.

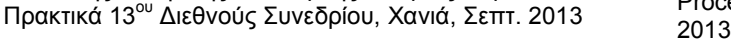

\title{
STOCHASTIC ANALYSIS OF EARTHOUAKE ACTIVITY IN TWO SEISMOGENIC FAULT SYSTEMS IN GREECE
}

\author{
Gkarlaouni Ch. ${ }^{1}$, Papadimitriou E. ${ }^{1}$, Lasocki ${ }_{3}{ }^{2}{ }^{2}$, Lizurek G. ${ }^{2}$, Karakostas V. \\ and Kilias A. ${ }^{3}$ \\ ${ }^{1}$ Geophysics Department, School of Geology, Faculty of Exact Sciences, Aristotle University of \\ Thessaloniki, GR54124, Thessaloniki, Greece \\ ${ }^{2}$ Institute of Geophysics, Polish Academy of Sciences, Księcia Janusza 64, \\ 01452, Warsaw, Poland \\ ${ }^{3}$ Geology Department, School of Geology, Faculty of Exact Sciences, Aristotle University of \\ Thessaloniki, GR54124, Thessaloniki, Greece
}

\begin{abstract}
Possible systematic variations in earthquake occurrence and fluctuations in seismicity behaviourof two seismically active regions in Greece which share common seismotectonic properties, is the aim of this study. Mygdonia graben in northern Greeceis characterized by arather moderate background seismicity, with small earthquakes between 2008-2012 whereas Corinth Gulf in southern Greece exhibits a constantly high seismicity rate with several seismic activations during the recent instrumental period or before. The statistical approach of seismicity was accomplished, regardingthe magnitude, the inter-event time and distance for recent seismicity as a tool to quantify complex earthquake occurrence ordense spatial and temporal clustering. For this reason, complete catalogues were compiled for the time period of the study. Probabilistic tests such as the smoothed bootstrap test for modality and bump-hunt were employed in order to unveil the complexity of the probability density function distribution of the above parameters. On the other hand spatial earthquake distribution wasalso investigated under the frameof their fractal properties since the fractal coefficientcan largely express the clustering degree of seismicity. The goal of this stochasticanalysisis the quantification of the differentiationin seismicity propertiesinthese two important seismogenic normal fault populations in the back arc Aegean area.
\end{abstract}

Keywords:Seismicity, complexity, fault basins.

\section{Пєрí $\eta \psi \eta$}

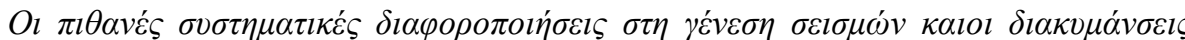

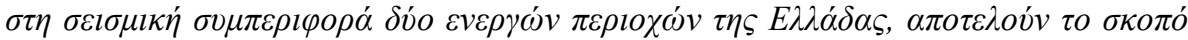

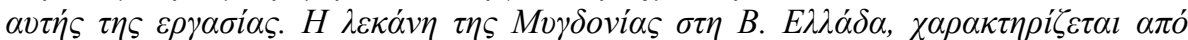

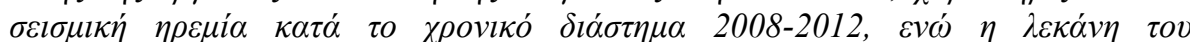

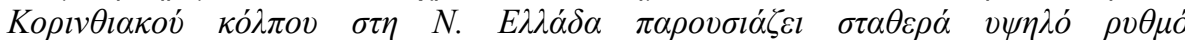

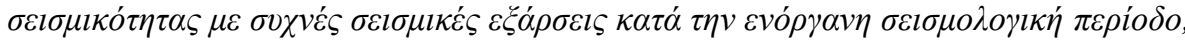

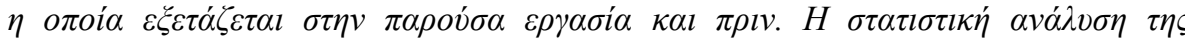

$\underline{\text { XLVII. No } 3 \text { - } 1099}$ 


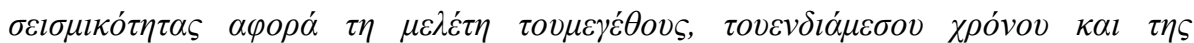

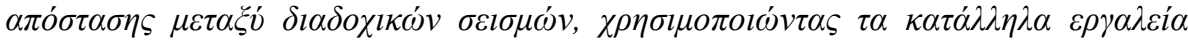

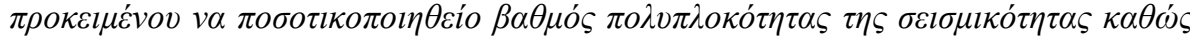

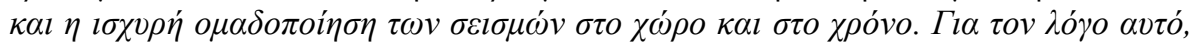

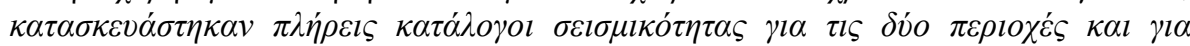

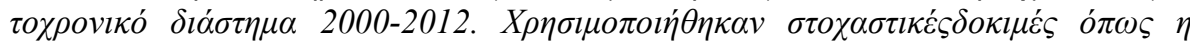

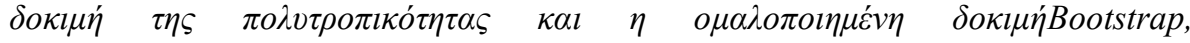

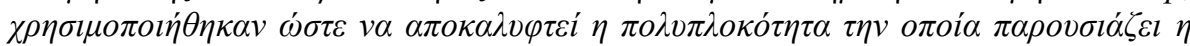

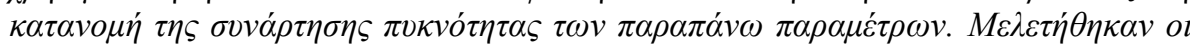

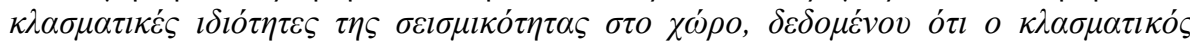

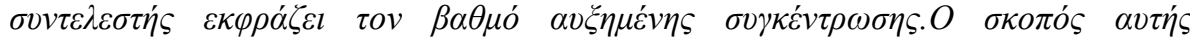

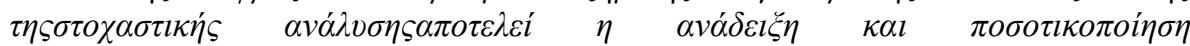

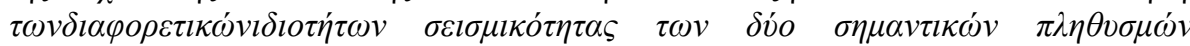

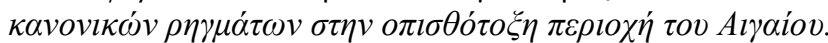

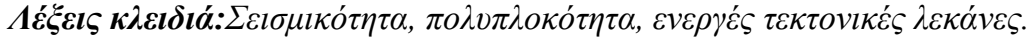

\title{
1. Introduction
}

Intensive researchwork has been conducted on the development of stochastic tools which among others investigatethesystematic properties of earthquake occurrence associated with the spatial, temporal and magnitude distribution of regional seismicity (e.g. Ogata, 1988; 1998; Console et al., 2006).Thisapproachis widely accepted and applied because of the urgent need to fully exploit all the available information and develop hypotheses on the systematics which govern seismicity processes at all scales, like clustering which is expressed as the dense occurrence of earthquakes and triggering between them. The stochastic approach of seismicity also reveals additional implications about the seismic behaviourof the causative fault systems which preferably prevail in each seismotectonic setting. The concern about seismicity systematics and their complicated behaviour stemmed from Omori law which expressed the time decay of aftershocks in time (Omori, 1894) and it was supplemented by the Gutenberg-Richter relation (Gutenberg and Richter, 1944) considering the frequency-magnitude distribution. Further modifications about G-R scaling law were proposed by Utsu(1999) whereasits temporal descriptionwasintroduced byBak et al.(2002). However, in each case, this analysis is susceptible to a variance of factors such as the seismotectonic framework of the study area,the seismologicalinstrumentation, the homogeneity and consistency of the seismic catalogue as well as the time period that the data refer to, and all of them enforce their impact on theresearch outcome.In our case, magnitude, time and space distribution, for two independent seismogenic zones located in the Greek mainland, Mygdonia basin (in Northern Greece) and Corinth Gulf (in Central Greece) bothsharing common seismotectonic properties and strong seismicity are investigated regardingtheir seismicity properties, such as the degree of clustering and complexity under the stochastic framework. In particular, the magnitude distribution of earthquakes as well as the lapse and the inter-event distance for consecutive pairs of earthquakes are investigated, taking into account the distribution of probability density function (PDF) of these parameters. The obtained results will provide a further insight into the seismicity behaviour in each case andwill be evaluated.

\section{Seismotectonic Setting}

The two study areas(Figure 1a), are located in the Greek mainland where strong extensional forces driven by the relative movement of microplates such asthe subduction and rolling-back of the eastern Meditterranean oceanic microplate along the South Hellenic Arc have given birth to the formation of numerous back - arc neotectonic basins, oriented perpendicular to the extensional stress axis. Geodetic and other measurements show that the deformation rate in the back-arc area,

$\underline{\text { XLVII, No } 3-1100}$ 
varies in space, therefore northern regions where Mygdonia region belongs (Figure 1b) demonstrate a reduced rate of deformation with rates equal to $1 \mathrm{~mm} /$ year (Kotzev et al., 2001) compared to the fast moving southern Aegean zone and the Corinth Gulf (Figure 1c) where extension dominates with rates equal to $1 \mathrm{~cm} / \mathrm{y}$ (Briole et al., 1993). However, important processes of fault nucleation and seismogenesis are taking place in both areas where North - South extension definesthe dominant pattern of active deformation.
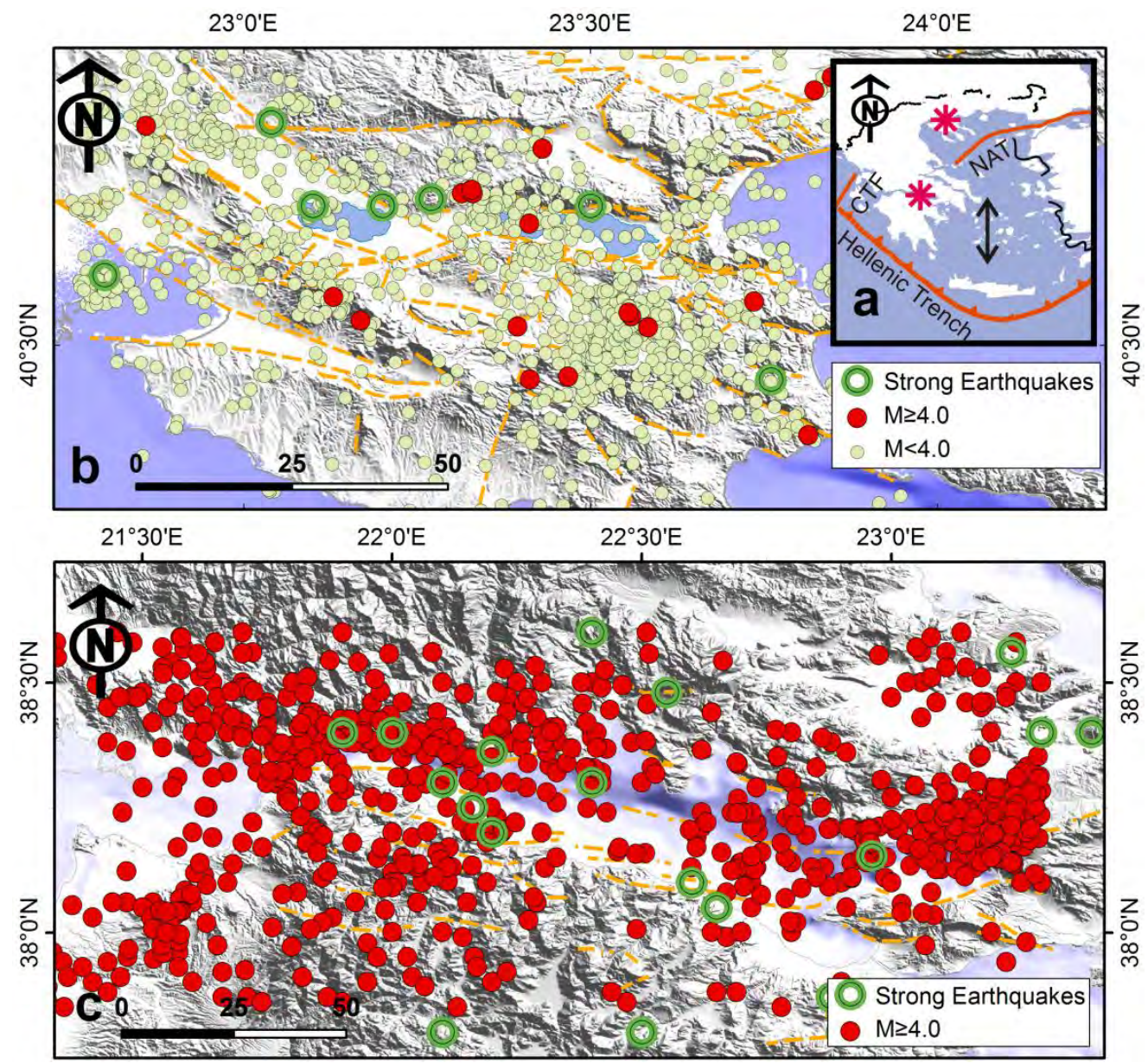

Figure 1 - a) Simplified seismotectonic map of the Aegean region (Hellenic Trench, NAF: North Aegean Trough, CTF: Cephalonia Transform Fault). The locations of the two study areasare highlighted with asterisksb) Mygdonia region in Northern Greece and c) Corinth gulf in Central Greece. Green circles correspond to strong historical earthquakessince 1700

(Papazachos and Papazachou, 2002). Earthquakes with strong magnitudesduring2000 -

\section{2are alsoillustrated.}

Mygdonia basin and the surrounding mountainous volumes accomodate a dense normal faulting network mainly developed in an E-W direction especially in the central part of the basin (Tranos et al., 2003) and is recently characterized by earthquake quiescence sincerecent seismicity is deprived of strong earthquakes after the occurrence of 1978 (M6.5) strong seismic triplet and Arnea Earthquake in $1995\left(\mathrm{M}_{\mathrm{w}} 5.8\right)$. However, according to the historical record the area was repeatedly struck by moderate and strong events in the past, and thus this information evidences the necessity of a thoughtful investigation of seismicity by all available means. 
Our second study area, Corinth graben constitutes a half graben bounded by segmented normal faults in an E-W direction dipping both to the North and the Southwith the southern faults to be the most active ones (Armijo et al., 1996).Constantlyintense seismicity and several strong earthquakes accompanied by aftershock sequences occurred in the last years (Achaia, $\mathrm{M}_{\mathrm{w}}=6.4,2008$; Efpalio, $\mathrm{M}_{\mathrm{w}}=5.5$, 2010; Xilokastro, $\mathrm{M}_{\mathrm{w}}=5.0,2012$ ).

\section{Data}

Differentiations in seismological networks and magnitude estimation through time have an influence on the long-term distribution of magnitudes and finally contribute to the different completeness threshold. The compilation of precisely defined focal earthquake parameters along with complete and homogeneous data sets seem to be a primal and fundamental step before exploiting seismicity catalogues. The data used, include all the earthquakes that occurred during 2008-2012 in the study areas and were instrumentally recorded by the Unified National Seismological Network of Greece. Thisstudy period was selected because it coincides with the higheraccuracy and stability of the permanently operated seismological network. These improvements, undoubtedly lead to a significant lowering of the magnitude threshold for detecting earthquakes. The magnitude threshold was found equal to $\mathrm{M}_{\mathrm{C}}=1.6$ for Mygdonia region (Figure 2a) and equal to $\mathrm{M}_{\mathrm{C}}=2.4$ for Corinth Gulf(Figure $2 \mathrm{~b}$ ) by applying the algorithm ofLeptokaropoulos et al. (2012) for the best linear fit (method by Wiemer and Wyss, 2002).Magnitudes were acquired from the monthly bulletins of the Seismological Station (A.U.Th.) and they refer to $M_{L}$ magnitude obtained by applying the methodology of Hutton and Boore (1987) on simulated Wood Anderson earthquake recordings.
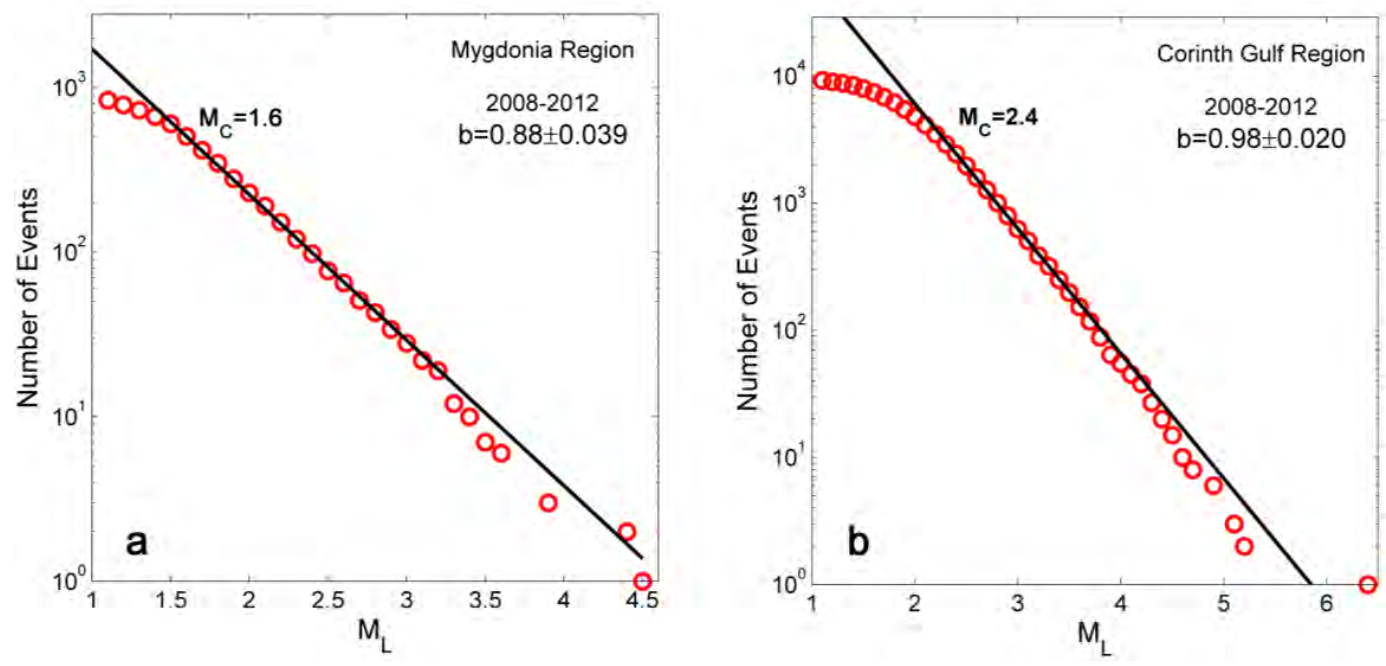

Figure 2 - Cumulative frequency-magnitude distribution (FMD) of earthquakes for the two study areas for the time period 2008-2012The completeness threshold is determined by detecting the smaller residual for a maximum likelihood estimation fitting a) FMD for Mygdonia Region, where $M_{C}=1.6$ b) FMD for Corinth Gulf Region, where $M_{C}=2.4$.

There is strong evidence that in a case of seismic excitations there is always an increased probability for aftershock sequences to occur. This dense occurrence of earthquakes in time and space is often misleading when long term variations and clustering are being studied because the degree of clustering phenomenais amplified. For this reason in the case of Corinth Gulf, Reasenberg's declustering algorithm (Reasenberg, 1985) wasapplied for the compilation of a catalogue data set deprived as possible of aftershock sequences. However, as far as the magnitude distribution is concerned tests wereapplied to both data sets(the initial set and the declustered) in 
order to investigate the properties of both catalogues and provide a comparison between them, if any.

\section{Methodology used}

\subsection{Smoothed Bootstrap Test}

The methodology adopted for the investigation of the PDF of the studied parameters, concerns the smoothed bootstrap test for multimodality and the bump hunt test, which isa non-parametrical procedure(fully described by Lasocki and Papadimitriou, 2006). The methodology (Silverman, 1986; Efron and Tibshirani 1994) has been applied in both fields of mining (Lasocki and OrleckaSikora, 2008) and natural seismicity (Lasocki and Papadimitriou, 2006). The method firstly investigates the distributionon the existence of modes or bumpsand secondly their number, since it is hypothetically stated that the distribution is not complex.Two hypotheses are assumed: $H_{1}^{0}$ presents the hypothesis that the probability density of magnitude distribution is unimodal, whereas $H_{2}^{0}$ refers to the assumption that the probability density of magnitude has one bump to the right from the mode.The distribution complexity, revealing multimodality, is accepted when the significance of either of these null hypotheses is low. Briefly, in a non-parametric approach the kernel estimator of probability density function $\hat{f}$ given byEquation 1 where, $M_{i}$ is the magnitude of $n$ given data, $h$ is a positive smoothing factor and $K(\bullet)$ is a kernel function strongly dependable on $h$.

Equation 1 - The kernel estimator of probability density function, $\hat{f}$

$$
\hat{f}\left(M \mid\left\{M_{i}\right\}, h\right)=\frac{1}{n h} \sum_{i=1}^{n} K\left(\frac{M-M_{i}}{h}\right)
$$

To determine the significance of the two hypothesesit is necessary to determine the critical smoothing factor, $h_{\text {crit }}(l), l=1,2$ such that there is only one mode or bump, for every $h \geq h_{\text {crit }}(l)$ for the two hypotheses, respectively.A number of smoothed bootstrap samplesderived from the original data sets, are compiled in order to approximate the significance of the two assumptions.

\subsection{Fractal Dimension}

The fractal dimension $D_{F}$ expressesthe degree of object clustering and is widely used in seismicity in order to quantify possible dense occurrence of earthquakesin time or space (Kagan and Jackson, 1991). Fractal geometry was first introduced by Mandelbrot (1983) who attempted to characterize self-similar properties of scale independent sets of data. The fractal analysis in this study is performed with the use of the algorithm introduced by Grassberger and Procaccia (1983) according to which, a volume containing $\mathrm{N}$ objects, earthquakes in this case, which correspond

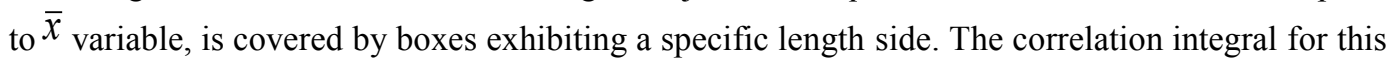
variable is given by the Equation 2, where $\left\|\bar{x}_{i}-\bar{x}_{k}\right\|$ is the measured distance between two earthquakes $i$ and $k$ in the $\vec{x}$ domain, $r$ corresponds to a reference distance and $\Theta(\bullet)$ refers to the known Heaviside function.The correlation integral, which behaves as a power to $r$ is proportional to the fractal dimension and is defined from the linear part of $-\log r$ empirical relation. When the studied objects are scale invariant, the number $N(r)$, of boxes covering the objects scales with $\mathrm{r}$ is given by $D_{F}$, which corresponds to the fractal dimension. 
Equation 2 - The Correlation integral which is proportional to the fractal dimension

$$
C^{(2)}(r)=\frac{1}{N(N-1)} \sum_{i=1}^{N} \sum_{k \neq i} \Theta\left(r-\left\|\vec{x}_{i}-\vec{x}_{k}\right\|\right)
$$

This parameter illustrates the degree of clustering of a set of objects and is used to express their similarities or heterogeneities. In our case, the parameter that is investigated in terms of fractal analysis using the methodology above, concerns the two dimensional spatial distance between consecutive events.

\section{Test Results}

\subsection{General}

The above described methodologies were employed in the current study because they provide a direct indication about the complexity of the parametersdistribution that are examined and can besuccessfully revealed under the frameof stochastic means. In this chapter, the outcome of this investigation in the two study regions is presented and the expectation of rejecting the initial hypotheses are analysed.Parameters like size, interevent time and interevent distance are examined with the use of smoothed bootstrap test for multimodality and bump hunt, whereas the spatial distribution of epicentres is investigated with the use of the fractal dimension in a two dimensional space.

\subsection{Size Distribution}

The smoothed bootstrap multimodality test was applied in three data sets,two of them corresponding to complete catalogues of the two study areas and the thirddeprived of aftershocks(Corinth Gulf). The same procedure was followed in all cases and thus 1000 bootstrap samples were compiled in order to estimate the significance of the null hypothesis. Rejecting the null hypothesis does not claim the existence of the alternative hypothesis, however, when the estimated probability is less than 0.15 the significance of this state depends on the value of $H_{1}^{0}$. In every casethat the size distribution is complex, revealing more than one bumpor mode, the location of the minimum and maximum points provide information onthe evolution of the seismicity processes and the prevalence of certain magnitudes. Two smoothing factors, $\mathrm{h}_{\text {crit }}$ and $\mathrm{h}_{\text {critb }}$ were calculated for both real and calibrated data and the resulting analysis for the three cases isprovided in Table 1 and Figure 3.

Table 1 -Results for the smoothed bootstrap test for multimodality and the bump hunt test, applied for magnitude PDF where $M_{C}$ is the magnitude threshold, $n$ is the number of the data in each sample and $\mathrm{H}_{1}{ }^{0}, \mathrm{H}_{2}{ }^{0}$ is the significance of the tests. For the case of rejecting null hypothesis the location of modes or bumps according to the test are given.

\begin{tabular}{|c|c|c|c|c|c|c|c|c|c|c|c|}
\hline \multirow{3}{*}{$\begin{array}{l}\text { Study Area } \\
\text { Mygdonia }\end{array}$} & \multirow{3}{*}{$\begin{array}{l}\mathbf{M}_{\mathbf{C}} \\
1.6 \\
\end{array}$} & \multirow[b]{3}{*}{505} & \multirow{3}{*}{$\begin{array}{l}\text { herit } \\
0.246\end{array}$} & \multirow{3}{*}{$\begin{array}{l}\mathbf{H}_{\mathbf{1}}^{\mathbf{0}} \\
0.19\end{array}$} & \multirow{3}{*}{$\begin{array}{l}\text { herit }_{\mathbf{b}} \\
0.363\end{array}$} & \multirow{3}{*}{$\begin{array}{l}\mathbf{H}_{\mathbf{2}}^{\mathbf{0}} \\
0.06\end{array}$} & \multicolumn{5}{|c|}{$\begin{array}{c}\text { Location of Modes or } \\
\text { Bumps }\end{array}$} \\
\hline & & & & & & & \multicolumn{3}{|c|}{ Modes } & \multicolumn{2}{|c|}{ Bumps } \\
\hline & & & & & & & \multicolumn{3}{|c|}{-} & 2.1 & 4.2 \\
\hline Cor. Gulf & 2.4 & 2446 & 0.443 & 0.12 & 0.505 & 0.08 & 2.7 & 6.2 & 6.3 & 3.1 & 6.2 \\
\hline $\begin{array}{l}\text { Cor. Gulf } \\
\text { (decl.) }\end{array}$ & 2.2 & 2248 & 0.434 & 0.12 & 0.520 & 0.01 & 2.4 & 6.0 & 6.3 & 2.9 & 6.1 \\
\hline
\end{tabular}



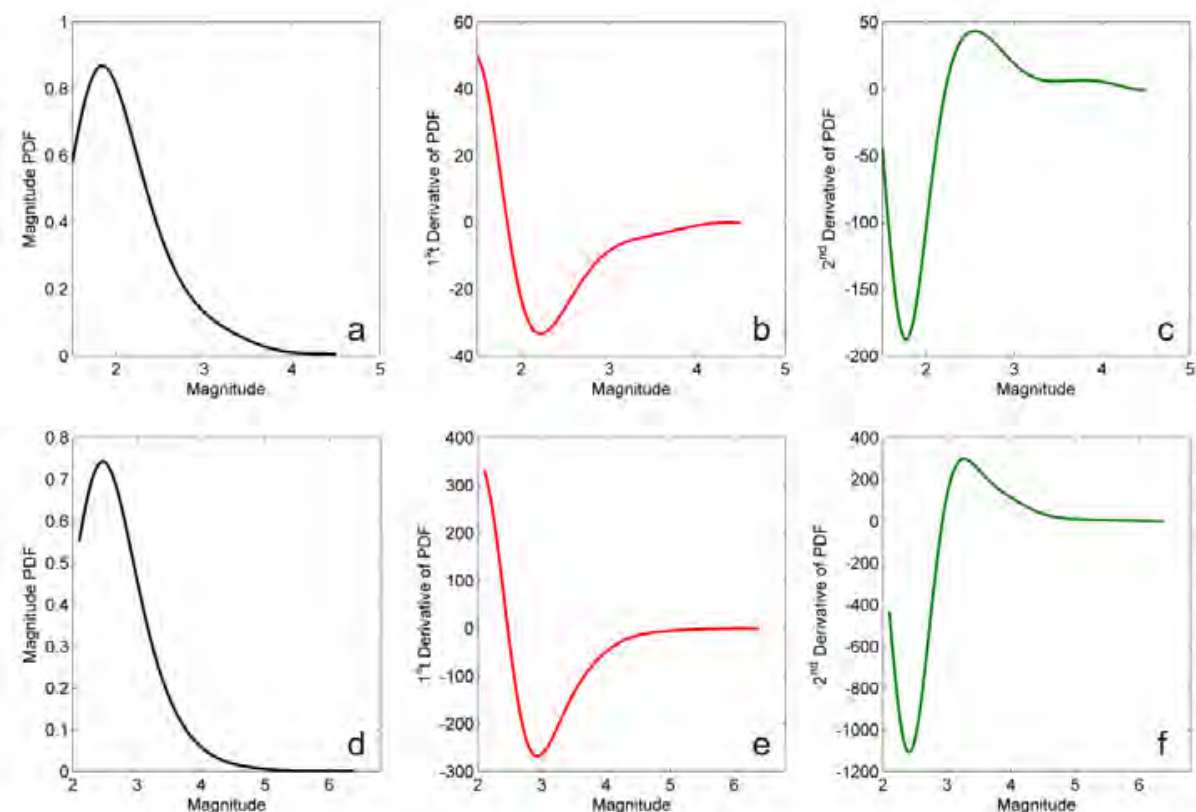

Figure 3-a) The magnitude PDF for Mygdonia region, b)The $1^{\text {st }}$ derivative of PDF, c) the $2^{\text {nd }}$ derivative of PDF, d) The magnitude PDF for Corinth region, e) The $1^{\text {st }}$ derivative of PDF and $f$ ) the $2^{\text {nd }}$ derivative of PDF estimated using the declustered catalogue.

ThePDF distribution shows that there is not an important indication for complexity and mode existence in the case of magnitudes in Mygdonia,however the significance of characteristic more than one bumpsappearance is important $\left(\mathrm{H}_{2}{ }^{0}: 0.06\right)$ and suggests that there is a $6 \%$ percentage of failing when the null hypothesis about uniformity is rejected. The bumps in the distribution correspond to lower real magnitudes than expected according to G-R law and are located at $\mathrm{M}=2.2$ and $M=4.2$. On the other hand,in both data sets forCorinth Gulf it is observed that both null hypotheses for unimodality are rejected and multiple modes and bumps are present in both cases ( since $\mathrm{H}_{1}{ }^{0}$ and $\mathrm{H}_{2}{ }^{0}<0.15$ ). Characteristic clustering of magnitudes is observed at small magnitudes in both cases $(2.7,2.4)$ and at the highest magnitudeslocated in the tail of the PDF distribution. It is observed that in the case of the declustered data modes and bumps are met at lower magnitudes compared to the original set.

\subsection{Interevent Distance Distribution}

The interevent distance, $\Delta \mathrm{s},\left(\Delta \mathrm{s}=\mathrm{r}_{(\mathrm{i}+1)}-\mathrm{r}_{\mathrm{i}}\right)$, corresponds to the respective distance of one event from its preceding, within the Euclidian space. Investigation of the distribution of theinterevent distance PDF provides a measurement of quantification of earthquake clustering in space and a degree of relativity and interaction between epicentres close in space.Results of the tests are presented in Table 2. It can be deduced that there is an indication of modes and bumps in the spatial distribution because the probability that the null hypothesisto be real scenario is important in the case of Mygdonia, while in the case of Corinth gulf it remains doubtable.

\subsection{Interevent Time Distribution}

The distribution of the lapse time, $\mathrm{dt}$, between a pair ofconsecutive events, that corresponds to the time that mediates the occurrence of two consecutive earthquakes, $\tau=t_{(i+1)}-t_{i}$, was also examined. In the last years, the analysis of waiting times between subsequent earthquakes was the subject of various works (Corral, 2006) supporting that the use of interevent time is beneficial since it is deprived of relative errors that origin time carries and may describecharacteristic attributes depending on the study area(Jonsdottir et al., 2006). The investigation of the multimodality test for 
this temporal parameterreveals that the behaviour of seismicity in time is not occurring in a uniform way in the two cases as it can be observed at Table 3.In Mygdonia the possibility of mistake, when rejecting the unimodal distribution hypothesis is about $11 \%$ and in Corinth even smaller. Therefore, there is stronger evidence that interevent time distribution is complex in both cases.

Table 2 -Results for the smoothedbootstrap test for multimodality and bump hunt test, for interevent distance PDF between consecutive events, where $M_{C}$ is the magnitude threshold, $n$ is the numberof the data in each sample and $\mathrm{H}_{1}{ }^{0}, \mathrm{H}_{2}{ }^{0}$ is the significance of the tests.

\begin{tabular}{|c|c|c|c|c|c|c|c|c|c|c|c|}
\hline \multirow{3}{*}{$\begin{array}{c}\begin{array}{c}\text { Study } \\
\text { Area }\end{array} \\
\text { Mygdonia } \\
\end{array}$} & \multirow{3}{*}{$\begin{array}{r}\mathbf{M}_{\mathbf{C}} \\
1.6 \\
\end{array}$} & \multirow{3}{*}{$\begin{array}{c}\mathbf{n} \\
505 \\
\end{array}$} & \multirow{3}{*}{$\begin{array}{l}\text { herit } \\
0.002 \\
\end{array}$} & \multirow{3}{*}{$\begin{array}{l}\mathbf{H}_{\mathbf{1}}{ }^{\mathbf{2}} \\
0.04\end{array}$} & \multirow{3}{*}{$\begin{array}{l}\text { hcrit }_{\mathbf{b}} \\
0.002\end{array}$} & \multirow{3}{*}{$\begin{array}{l}\mathbf{H}^{{ }^{\mathbf{0}}} \\
0.15\end{array}$} & \multicolumn{5}{|c|}{ Location of Modes or Bumps } \\
\hline & & & & & & & \multicolumn{3}{|c|}{ Modes } & \multicolumn{2}{|c|}{ Bumps } \\
\hline & & & & & & & 0.0012 & 0.037 & 0.051 & 0.09 & 0.011 \\
\hline $\begin{array}{l}\text { Cor. Gulf } \\
\text { (decl.) }\end{array}$ & 2.2 & 2248 & 0.002 & 0.17 & 0.003 & 0.18 & & - & & & - \\
\hline
\end{tabular}

Table 3 -Results for the smoothedbootstrap test for multimodality and bump hunt test, for interevent distance PDF between consecutive events, where $M_{C}$ is the magnitude threshold, $n$ is the number of the data in each sample and $\mathrm{H}^{0}{ }_{1}, \mathrm{H}^{0}{ }_{2}$ is the significance of the tests.

\begin{tabular}{|c|c|c|c|c|c|c|c|c|c|c|}
\hline \multirow{3}{*}{$\begin{array}{l}\text { Study Area } \\
\text { Mygdonia }\end{array}$} & \multirow{3}{*}{$\begin{array}{l}\mathbf{M}_{\mathbf{C}} \\
1.6\end{array}$} & \multirow{3}{*}{$\begin{array}{c}\mathbf{n} \\
505\end{array}$} & \multirow{3}{*}{$\begin{array}{l}\text { herit } \\
14.60\end{array}$} & \multirow{3}{*}{$\begin{array}{c}\mathbf{H}_{\mathbf{1}}{ }^{\mathbf{1}} \\
0.108\end{array}$} & \multirow{3}{*}{$\begin{array}{r}\text { hcrit }_{\mathbf{b}} \\
17.78\end{array}$} & \multirow{3}{*}{$\begin{array}{c}\mathbf{H}_{\mathbf{2}}{ }^{\mathbf{2}} \\
0\end{array}$} & \multicolumn{4}{|c|}{ Location of Modes or Bumps } \\
\hline & & & & & & & \multicolumn{2}{|c|}{ Modes } & \multicolumn{2}{|c|}{ Bumps } \\
\hline & & & & & & & 5.7 & 9.6 & 4.76 & 6.34 \\
\hline $\begin{array}{l}\text { Cor. Gulf } \\
\text { (decl.) }\end{array}$ & 2.2 & 2248 & 1.00 & 0.24 & 1.46 & 0.011 & & & 2.12 & 10.38 \\
\hline
\end{tabular}

\subsection{Spatial Distribution}

Long term spatial clustering was approached with the investigation of fractal properties for the two dimensional space of the seismogenic volume and the fractal dimension of the earthquake epicentral distribution for the complete earthquake catalogue. The calculation of the fractal dimension derives from the double logarithmic plot between the correlation dimension and the Euclidian distance located on a planar surface upon which the epicentres were projected. This approach is close to reality since the study area is not very extended and can be approximated with a planar surface. As mentioned before, the correlation integral corresponds to the best fittedleastsquare regression line to the linear part of the slope of a $\log -\log$ plot.Clustering is as stronger as smaller the value of the corresponding fractal dimension.Results are presented in Figure 4. The fractal dimension in two-dimensional space was found equal to 1.3 for both areas. In Figure 4 the linear part of the plots without the minimum and maximum cutoff of the logarithmic plot are presented.The fractal dimensions of three dimensional data including focal depths were excluded from the calculations, since it seems that focal depths are concentrated in a specific band of the crust, i.e. the seismogenic layer, and they do not provide any additional information.

\section{Discussion}

The stochastic approach of seismicity along with faulting identification studies both share the satisfying determination of a potential threat in a seismogenic region (Ouillon and Sornette, 2011).Therefore, the target of our study was the full exploitation of seismicity data for two seismo- 

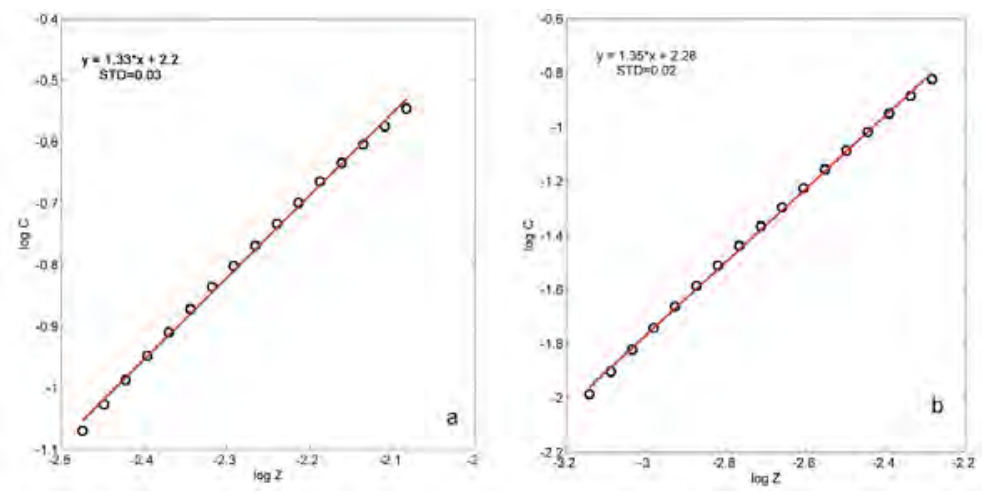

Figure 4 - Fractal Dimension of the two-dimensional spatial distribution where $\operatorname{lgC}$ and $\operatorname{lgZ}$ correspond to the logarithm of the distance reference and the distance for a) Mygdonia and b) Corinth Gulf region.

genic regions in Greece, one exhibiting a seismic quiescenceperiod with the maximum magnitude 4.8 and the other experiencing strong seismicity with maximum magnitude equal to 6.4. Accurate complete data for the study period where taken into consideration and the tools chosen for this purpose concern methodologies that were applied in regions with low magnitudes and localized earthquakes such as mines. Bootstrap techniques are the most suitable to be used because of the resampling process of the imported data, despite the small seismicity sample. The aim of this approach was the quantification of clustering effects of seismicity, in two cases, with or without main strong events. The smoothed bootstrap testfor the probability density function of magnitudes, interevent time and space shows a strong evidence for a multi-modes shape, leading to the conclusion that both regions behave in the same way without a uniform occurrence of small and stronger events. Maximum concentrations of magnitudes are met at lowest magnitudes $(2.7,2.4)$ of the distribution as well as in the tails. The probabilistic analysis for time and distance in general are not contradictory to the results obtained from the fractal analysis. Interevent time and interevent space depicts a multi mode shape with three distinct locations of modes, for all cases, however in Gorinth gulf there is not a characteristic interevent time distance between events. According to the fractal dimensions, their values do not exhibit significant variations in the two areas, or in the entire study area and clustering in the spatial distribution of epicentres in the entire study area is evident and strong enough. Even in the case of Mygdonia small earthquakes trigger the occurrence of each other along their neighbour faults. There was a complete use of all available data, and observations seem to be in a good agreement thus complexity was revealed in both study areasdespite the rate of seismicity, with different characteristic properties for each case.

\section{Acknowledgments}

This work was co-financed by the European Union (European Social Fund-ESF) and Greek national funds through the Operational Program "Education and Lifelong Learning" of the National Strategic Reference Framework (NSRF) - Research Funding Program: Heracleitus II Investing in knowledge society through the European Social Fund.Geophysics Department contribution 000 .

\section{References}

Armijo R., Meyer B., King G.C.P. Rigo A. and Papanastassiou D. 1996. Quaternary evolution of the Corinth Rift and its implications for the Late Cenozoic evolution of the Aegean, Geophys J. Int., 126, 11-53.

Bak P., Christensen K., Danon L. and Scanlon T. 2002. Unified scaling law for earthquakes, Phys. Rev. Lett., 88, doi:10.1103/PhysRevLett.88.178501.

$\underline{\text { XLVII, No } 3-1107}$ 
Briole P., Rigo A., Lyon-Caen H., Ruegg J.C., Papazissi K., Mitsakaki C., Balodimou A., Veis G., Hatzfeld D. and Deschamps A. 2000. Active deformation of the Corinth rift, Greece: results from repeated Global Positioning System surveys between 1990 and 1995, J. Geophys. Res., 105, 25605-25625.

Console R., Murru M. and Catalli F. 2006. Physical and stochastic models of earthquake clustering, Tectonophysics, 417, 1-2, 141-153.

Coral A. 2006. Dependence of earthquake recurrence times and independence of magnitudes on seismicity history, Tectonophysics 424, 177-193.

Efron B. and Tibshirani R.J., 1993/1998. An Introduction to the Bootstrap, Chapman and Hall, London

Grassberger P. and Procaccia I. 1983. Characterization of strange attractors, Phys. Rev. Lett., 50, 346-349.

Gutenberg B. and Richter C.F. 1944. Frequency of earthquakes in California, Bull. Seismol. Soc. Am,. 34 185-188.

Hutton L.K. and Boore D.M. 1987. The M scale in southern California, Bull. Seismol. Soc. Am., $77,2074-2094$.

Jonsdottir K., Lindman M., Roberts R., Lund B. and Bödvarsson R. 2006. Modelling fundamental waiting time distributions for earthquake sequences, Tectonophysics, 424, 195-208.

Kagan Y.Y. and Jackson D.D. 1991. Long-term earthquake clustering, Geoph. J. Int., 104, 117133.

Kotzev V., Nakov R., Georgiev Tz., Burchfiel B.C. and King R.W. 2001. Crustal motion and strain accumulation in western Bulgaria, Tectonophysics, 413, $189-200$.

Lasocki S. and Orlecka-Sikora B. 2008. Seismic hazard assessment under complex source size distribution of mining-induced seismicity, Tectonophysics, 456, 28-37.

Lasocki S. and Papadimitriou E. 2006. Magnitude distribution complexity revealed in seismicity from Greece, J. Geophys. Res., 111,B11309, doi:10.1029/2005JB003794.

Leptokaropoulos K. Karakostas V. Papadimitriou E. Adamaki A. Tan O. and Inan S. 2012. A homogeneous earthquake catalogue compilation for western Turkey and magnitude completeness determination (submitted manuscript).

Mandelbrot B.B. 1983. The fractal geomtery of nature, Freeman, San Francisco, 468 pp.

Ogata Y. 1988. Statistical models for earthquake occurrence and residual analysis for point process, J. Am. Stat. Assoc. 83, 9-27.

Ogata Y. 1998. Space-time point-process models for earthquake occurrences, Ann. Inst. Stat. Math. 50, 379-402.

Omori F. 1894. On aftershocks of earthquakes, J. College Sci. Imp. Univ., Tokyo 7, 111-200.

Papazachos B.C. and Papazachou C. 2002. The earthquakes of Greece, Ziti Publ., Thessaloniki, Greece, 317pp.

Ouillon G. and Sornette D. 2011.Segmentation of fault networks determined from spatial clustering of earthquakes, J. Geophys. Res., 16, doi:10.1029/2010JB007752.

Reasenberg P. 1985. Second-order moment of central California seismicity, 1969-1982, J. Geophys. Res., 90, 5479- 5495.

Silverman B.W. 1986. Density Estimation for Statistics and Data Analysis, Monographs on Statistics and Applied Probability, Chapman and Hall, London, 175 pp.

Tranos M., Papadimitriou E. and Kilias A. 2003. Thessaloniki-Gerakarou fault zone (TGFZ): the western extension of the 1978 Thessaloniki earthquake fault (northern Greece) and seismic hazard assessment, J. Struct. Geol., 25, 2109-2123.

Utsu T. 1999. Representation and analysis of the earthquake size distribution: a historical review and some new approaches, Pure Appl. Geophys., 155, 509-535.

Wiemer S. and Wyss M. 2000. Minimum magnitude of completeness in earthquake catalogs: examples from Alaska, the Western United States, and Japan, Bull. Seismol. Soc. Am., 90, $859-869$ 